\title{
SWOT ANALYSIS OF THE TOURIST SECTOR ON PAROS ISLAND, GREECE
}

\author{
DIMITRIS PROKOPIOU ${ }^{1}$, KONSTANTINOS GIANNOPOULOS ${ }^{2}$, KONSTANTINOS ANAGNOSTELLOS ${ }^{3}$, \\ BASIL TSELENTIS $^{1} \&$ GEORGE MAVRIDOGLOU $^{4}$ \\ ${ }^{1}$ Department of Maritime Studies, University of Piraeus, Greece \\ ${ }^{2}$ Harokopio University, Greece \\ ${ }^{3}$ Economist, Greece \\ ${ }^{4}$ Department of Accounting and Finance, University of Peloponnese, Greece
}

\begin{abstract}
The tourism industry is one of the most important economic activities for Greece. Over 25 million tourists per year visit Greece. This means that at the peak of the season, July and August, the number of visitors equals the number of people in the country's population: about 10 million. One of the most famous tourist destinations in Greece is Paros, in the Cyclades island archipelago. Tourist development requires a multi-disciplinary approach, because it is a function that includes a wide range of actors, such as: the natural resources; ecosystem management; and the effects of human activities on fauna, flora and the coastal zone; as well as economic and social parameters. For the Greek islands, the environment, especially that of the coastal zones, plays a crucial role in keeping the tourism industry. This is reflected in the volume of scientific research that focuses on the study of the environmental impact of tourist development, as there are many entrepreneurs in the tourist industry that are trying to enlarge the tourist product. The purpose of this paper is to examine the present and the future of tourism in Paros, according to environmental indexes, living conditions and the condition of the tourist product itself.

Keywords: carrying capacity, coasts, coastal zones, Cyclades, economy, ecosystems, environment, environmental impact, Greece, islands, Paros, tourism, tourism marketing.
\end{abstract}

\section{INTRODUCTION}

Greece depends heavily on the tourist sector, as $20 \%$ of the country's gross domestic product (GDP) comes from the tourism industry. Tourist activity focused on Athens and other archaeological sites extend mainly to island Greece. Great tourist development over the past 60 years took place on a group of islands named the Cyclades, which refers to the islands forming a circle [circular islands] around the sacred island of Delos, in the Aegean archipelago. They are one of the island groups which constitute the Aegean archipelago.

Paros is one of the most popular holiday destinations for visitors to the Greek islands. It neighbors Naxos and is the third largest island of the Cyclades, after Andros and Naxos, with an area of $196 \mathrm{~km}^{2}$ and a coastline that is $120 \mathrm{~km}$ long. The island is the third in popularity, after Santorini and Mykonos. Paros is considered as one of the most beautiful islands of the Cyclades. It is characterized by many beaches and also its charming villages: Paroikia, Naoussa, Lefkes and Marpissa. Tourism development has greatly changed the lives of island residents, as poor farmers and fishermen have acquired other professional activities, the administration has created an infrastructure with ports, roads, etc. Demand for tourist services has led to the development of accommodations, restaurants, and the economic exploitation of beaches. The risk of unsustainable growth due to overexploitation has been and is great.

The challenge for sustainable development of the Cyclades islands is to find a balance between tourism development, the environment and the quality of life of residents; as the tourist product is a blend of ecological, social and economic sub-systems [1].

The natural environment is crucial to the attractiveness of almost all travel destinations and recreation areas [2]. Coastal and marine areas are important recreation resources for both 
local residents and tourists, who spend much time doing marine activities [3]. Coastal zone management is emerging as a major concern for governments.

Carrying capacity assessment became an indispensable tool for formulating policy and strategies in the tourist industry, worldwide [4]. Countries and regions with considerable natural and cultural resources look towards tourism to stimulate their sustainable development activities. The contribution of the tourism sector to development needs to be clearly explained, to allow countries to invest in tourism. Tourism is considered as a development factor [5], and is probably the best example among human activities, in which the linkages between environmental quality and economic prospects are evident [6].

The purpose of this study is to examine the current state of Paros, by presenting the infrastructure and analyzing the interactions between tourism and the environment, by examining environmental indices [7]. The results will undergo a SWOT analysis, to examine the development potential of the tourist product in Paros.

\section{METHODOLOGY}

For measuring sustainability, an adapted number of indicators were selected and a comprehensive prototype model was created by the authors D. Prokopiou and B. S. Tselentis. In order to achieve the objective of the study, it was necessary to collect data on the economic effects of tourism development, as well as the social development of these areas within recent years. The measurement of the economic outcomes of tourism development were taken from the macroeconomic data of the region. The economic dimension can be measured by financial data provided by the Hellenic Statistical Authority and the Bank of Greece. The second dimension was measured by a combination of quantitative and qualitative data concerning the development and quality of life in the Cycladic islands [9].

For the environmental dimension, models from the international bibliography, including studies by Janvier-Blancas et al. [8], Hadjibiros et al. [10], and Petrosillo et al. [11] suggest adopting suitable indicators for an environmental impact assessment. In our study (Table 1), we used the Prokopiou-Tselentis model. The proposed model is based on sixteen variables that have values from 0-100 and is based on a Navaro Jurado, et al. [12] study regarding methodology to assess the carrying capacity of tourist destinations, for the creation of synthetic indicators applied in coastal areas.

Table 1: Environmental and infrastructure variables.

\begin{tabular}{|c|l|c|}
\hline Variable name & Description & Measurement \\
\hline V1 & Urban waste management & $0-100$ \\
\hline V2 & Legality of buildings & $0-100$ \\
\hline V3 & Protection against noise nuisance & $0-100$ \\
\hline V4 & Garbage management & $0-100$ \\
\hline V5 & Protection against pesticide usage & $0-100$ \\
\hline V6 & Over-pumping of seawater & $0-100$ \\
\hline V7 & Sufficient water resources & $0-100$ \\
\hline V8 & Sufficient quality of drinking water & $0-100$ \\
\hline V9 & Exposure to forest fires & $0-100$ \\
\hline V10 & Land clearing & $0-100$ \\
\hline V11 & Conservation of the landscape & $0-100$ \\
\hline V12 & Adequacy of green areas & $0-100$ \\
\hline
\end{tabular}


The Prokopiou Tselentis model uses a set of sixteen indicators to evaluate the environmental impact of tourism activities. These sixteen variables can be divided into two groups. The main objective of the first group of variables is the rating of environmental characteristics and infrastructure of the area. This group includes twelve out of the sixteen variables (Table 1). The second group consists of four variables (Table 2). The model was presented by Prokopiou in the European Scientific Journal [13] and in WIT Transactions on Ecology and the Environment [14].

Table 2: Environmental and infrastructure variables.

\begin{tabular}{|c|l|c|}
\hline Variable name & Description & Measurement \\
\hline V13 & Beds per kilometer of beach & $0-100$ \\
\hline V14 & Beds per square kilometer & $0-100$ \\
\hline V15 & Beds per inhabitant & $0-100$ \\
\hline V16 & Blue flags per kilometer of beach & $0-100$ \\
\hline
\end{tabular}

The score is derived by using questionnaires about and qualitative indicators of each area. The data was selected from the 31 municipalities and communities in the Cyclades Islands. Questionnaires were sent to all of these municipalities, for the purpose of the survey [15]. We received responses from everyone, so our research can be considered a census. The questionnaire listed the municipalities' environmental infrastructure, as well as their capabilities, natural resources and the nuisance from tourism development.

\section{PAROS ISLAND}

Paros lies almost at the center of the group of islands called the Cyclades and it is the third largest island there, after Naxos and Andros. Paros is an internationally well-known tourist destination for summer holidays, because of its natural beauty, nice beaches, extraordinary architecture, the sun and the Mediterranean climate. Before its tourist development, agriculture and fisheries were the main economic sectors in Paros; while in recent years, vineyard cultivation and wine production have experienced significant growth. The coastline is indented, with numerous small islets and two large sheltered bays, those of Paroikia in the west and Naoussa in the north. Around the island there are also a number of small ports that have taxi-boat services to the excellent beaches of the adjacent islands [16].

Paros' main port, tourist center and capital, Paroikia, is situated on the west coast. At its heart lies a typical Cycladic whitewashed "Hora" (island town), overlooked by the old walls of a Venetian castle built in 1207 AD on the site of the ancient Acropolis. Not far away is a $4^{\text {th }}$ century cathedral church of Panagia Ekatontapyliani, one of the most important Byzantine temples throughout Greece. Paros' second tourist center is Naoussa, a picturesque fishing village built around an old Venetian port [17].

\subsection{Arriving on the supply side}

Access to Paros is possible by both airplane and ferry. The old airport is located southeast of the island, $10 \mathrm{~km}$ from the city of Paroikia, and has been in operation since 1982. The old airport had a $710 \mathrm{~m}$ runway, sufficient for the small ATR aircraft that operated the Athens-Paros-Athens route, but when the number of passengers grew, the use of larger aircraft became necessary. 


\section{TOURISM}

To solve the problem, the decision was taken to build a new airport, very close to the old one. The new airport opened 25 July 2016, and it has a 1,400 m runway and three parking spaces for medium-sized aircraft (Q400), plus general aviation light aircraft parking spaces and one fire-fighting station. The one passenger terminal covers almost $600 \mathrm{~m}^{2}$.

Three Greek airlines (Aegean- OA, ASTRA and SKY Express) cover the domestic routes to Paros, from the Athens and Thessaloniki airports; and since 2018, a Czech and an Austrian charter airline operator also fly to Paros, during the summer, with a medium-sized jet.

Tourists can also get to Paros by boat from the two main Attica ports, Piraeus and Rafina, as well as from the Dodecanese ports, ports of Thessaloniki, Thira and from most of the other Aegean Islands. The main port on the island is located in Paroikia: about 40 vessels arrive and depart from Paroikia on a usual summer day. The barrier to the north protects the bay against adverse weather conditions: only strong winds from the west may sometimes create docking problems at the port. The Paroikia marina has the facilities to be able to serve both small and large speedboats, sailboats, yachts and fishing boats. Cruise ships also moor at the port, in summer. There are three more ports, Naoussa, Piso Livadi and Pounta. Naoussa, the second port of the island, operates an expansive, organized marina, with mooring for all types of vessels and excellent guest services. It can accommodate vessels with a maximum draft of $3 \mathrm{~m}$. Boats depart in the summer for day cruises to Tinos, Mykonos and Delos. Located in the south of the island, the Piso Livadi marina is protected from the strong northerly winds. The marina hosts fishing and tourist boats and is the starting point for excursions to Amorgos, Koufonisia and Santorini. Pounta connects Paros and Antiparos all year round. Ferries depart from both islands every 30 minutes: the crossing takes approximately 10 minutes.

\subsection{Arriving on the demand side}

Table 3 presents the domestic air traffic. According the table, since the day of operation of the new airport (July 2016), the number of passengers has increased dramatically.

Table 3: Domestic air traffic. (Source: Hellenic Civil Aviation Authority [24].)

\begin{tabular}{|c|c|c|c|c|c|}
\hline \multirow{2}{*}{ Year } & \multirow{2}{*}{$\begin{array}{c}\text { Flights } \\
\text { arrivals })\end{array}$} & Arrivals & Depart. & Freight (tonnes) \\
\cline { 3 - 6 } & 1110 & 21.475 & 14.954 & 0 & 0 \\
\hline 2013 & 1113 & 24.259 & 15.600 & 0 & 0 \\
\hline 2014 & 1133 & 27.218 & 15.964 & 1 & 0 \\
\hline 2015 & 1082 & 37.872 & 36.416 & 0 & 0 \\
\hline 2016 & 1594 & 73.526 & 86.845 & 14 & 0 \\
\hline 2017 & 92.734 & & & \\
\hline 2018 & & \multicolumn{3}{|c}{} \\
\hline
\end{tabular}

It should be noted that the number of arrivals for 2017 and 2018 do not include international arrivals. The number of passengers from international flights more than doubled, from 1,500 in 2017 to 3,340 in 2018. The operation of the new airport has already given new momentum to air arrivals. The challenge for the next years is to increase the use of the airport, as a door to tourist arrival to the island. As larger aircraft will be able to access the airport, this will allow expansion of the tourist season, with conference-related tourism.

The port remains the main form of entrance to the island, with an increase of about $30 \%$, from 2013 until today (Table 4). The docking of more cruise ships is our target for the future (Table 5), when the construction of a new terminal in the port is completed. 
Table 4: Tourist traffic for the port of Paros. (Source: INSETE [22].)

\begin{tabular}{|c|c|c|c|}
\hline Year & Arrivals & Departures & Total \\
\hline 2014 & 700.643 & 698.915 & 1.399 .558 \\
\hline 2016 & 708.427 & 729.652 & 1.438 .079 \\
\hline 2018 & 924.105 & 908.169 & 1.832 .274 \\
\hline
\end{tabular}

Table 5: Cruise ship traffic. (Source: INSETE [22].)

\begin{tabular}{|c|c|c|}
\hline Year & Cruise ships & Passengers \\
\hline 2013 & 88 & 7.071 \\
\hline 2015 & 25 & 3.679 \\
\hline 2017 & 16 & 3.916 \\
\hline 2018 & 17 & 2.476 \\
\hline
\end{tabular}

\subsection{Accommodation on the supply side}

The tourist development of Paros was not originally planned. Since the early 1960s, the island was developed as a summer tourist destination; and for all years, it was a famous holiday resort in Cyclades islands, for Greeks. From June to September there is an increase in money coming in due to the number of overnight stays, as visits are combined with the summer holidays and tourist traffic peaks, in July and August. Paros has more than 20,000 beds, concentrated around Chora and Naousa.

Table 6 shows the number of hotels, rooms and beds by hotel star category. What transpires is that there is a significant increase in the bed number in hotels with 3 or more stars, while the number of beds is declining in the other categories.

Table 6: Hotel capacity. (Source: INSETE [22].)

\begin{tabular}{|c|l|l|c|c|c|c|c|}
\hline \multirow{2}{*}{ Year } & \multirow{2}{*}{ Variable } & \multicolumn{5}{|c|}{ Stars } & \multirow{2}{*}{ Total } \\
\cline { 3 - 8 } & & $5^{*}$ & $4^{*}$ & $3^{*}$ & $2^{*}$ & $1^{*}$ & \\
\hline 1969 & & & & & & & 280 \\
\hline 1973 & Beds & & & & & & 104 \\
\hline 1977 & Beds & & & & & & 631 \\
\hline 1987 & Beds & & & & & & 1081 \\
\hline 2007 & Beds & & & & & & 6306 \\
\hline \multirow{3}{*}{2010} & Units & 2 & 14 & 20 & 87 & 23 & 146 \\
\cline { 2 - 8 } & Rooms & 96 & 714 & 656 & 1825 & 331 & 3622 \\
\cline { 2 - 8 } & Beds & 180 & 1331 & 1229 & 3491 & 662 & 6893 \\
\hline \multirow{3}{*}{2012} & Units & 2 & 15 & 20 & 87 & 23 & 147 \\
\cline { 2 - 8 } & Rooms & 96 & 708 & 653 & 1825 & 331 & 3613 \\
\cline { 2 - 8 } & Beds & 180 & 1318 & 1228 & 3491 & 662 & 6879 \\
\hline \multirow{3}{*}{2015} & Units & 2 & 18 & 30 & 76 & 21 & 147 \\
\cline { 2 - 8 } & Rooms & 96 & 832 & 894 & 1582 & 297 & 3701 \\
\cline { 2 - 8 } & Beds & 180 & 1533 & 1691 & 3042 & 595 & 7041 \\
\hline \multirow{3}{*}{2018} & Units & 4 & 19 & 37 & 64 & 21 & 145 \\
\cline { 2 - 8 } & Rooms & 211 & 848 & 1074 & 1263 & 297 & 3693 \\
\cline { 2 - 8 } & Beds & 411 & 1603 & 2109 & 2430 & 595 & 7148 \\
\hline
\end{tabular}


This is because of a shift to the provision of better and more expensive services. It is notable that there is an increase in rented rooms, by category (Table 7). The creation of new channels of communication with tourists via internet platforms (such as AirBnB, Booking, etc.) gives an incentive to have use of free residences and rooms. Paros also has six camping units, with a total of 441 tourist positions.

Table 7: Rooms for rent capacity. (Source: INSETE [22].)

\begin{tabular}{|c|c|c|c|c|c|c|}
\hline \multirow{2}{*}{ Year } & \multirow{2}{*}{ Variable } & \multicolumn{4}{|c|}{ Keys } & \multirow{2}{*}{ Total } \\
\cline { 3 - 6 } & & $4 \mathrm{~K}$ & $3 \mathrm{~K}$ & $2 \mathrm{~K}$ & $1 \mathrm{~K}$ & \\
\hline \multirow{3}{*}{2018} & Units & 84 & 192 & 517 & 117 & 910 \\
\cline { 2 - 6 } & Rooms & 607 & 1573 & 3371 & 662 & 6213 \\
\cline { 2 - 6 } & Beds & 1.549 & 3869 & 7920 & 1509 & 14,847 \\
\hline
\end{tabular}

\subsection{Accommodations, demand side}

Table 8 presents tourist accommodation data for hotels. According to these data, there has been an increase in the overnight stays of foreign tourists, while there is a significant reduction in domestic tourists. This may be due to the financial crisis that has been troubling Greece over the past 10 years. The total occupancy is low, as the tourist season is limited to 3 to 4 months, and some days during the Easter period.

Table 8: Arrivals, Overnight stays and occupancy of the hotels (2010-2017). (Source: ELSTAT [23].)

\begin{tabular}{|l|c|c|c|c|c|}
\hline \multirow{2}{*}{ Variable } & \multicolumn{5}{|c|}{ Year } \\
\cline { 2 - 6 } & 2010 & 2012 & 2014 & 2016 & 2017 \\
\hline Arrivals (foreign tourists) & 41,506 & 34,107 & 52,194 & 51,852 & 65,737 \\
\hline Arrivals (Greek tourists) & 35,694 & 19,044 & 19,720 & 21,241 & 24,252 \\
\hline $\begin{array}{l}\text { Overnight stays (foreign } \\
\text { tourists) }\end{array}$ & 172,724 & 147,217 & 227,458 & 220,797 & 278,143 \\
\hline $\begin{array}{l}\text { Overnight stays (Greek } \\
\text { tourists) }\end{array}$ & 142,764 & 77,411 & 96,763 & 80,157 & 80,923 \\
\hline Occupancy & $39.3 \%$ & $26.8 \%$ & $37.1 \%$ & $33.1 \%$ & $38.7 \%$ \\
\hline
\end{tabular}

According to room rental data from the AirDna platform, the occupancy is $38 \%$ of about 2000 accommodations. The average rental rate during the year is 111 euros.

\subsection{Paros: environment and tourism}

Paros is characterized by its many beautiful beaches: more than 25 in number. These include beaches that are ideal for windsurfing, like Gold Beach, and many beaches for water sports.

Many hiking trails will lead you around the island. The Byzantine street, as one of the island's main walking trails is called, will take you from the village of Prodromos, all the way to Lefkes, in a little over an hour. Beautiful hikes can be taken from the Agioi Anargyroi monastery in Parikia, via Thapsana and Agioi Pantes, to Lefkes. From the village of Lefkes, take the small path to the villages in the island's South, like Marpissa. Near the beach of Kolimpithres, take a walk to the lighthouse, at the island's Northernmost point. All these hikes can also be enjoyed with a mountain bike. 
Paros has unique scenery in the light of dawn, or during sunset, riding purebred horses on the island's beaches and along small village paths.

Paros also has nine museums, with a significant number of visitors (Table 9).

Table 9: Museum visitors. (Source: ELSTAT [23].)

\begin{tabular}{|c|c|}
\hline Year & Visitors \\
\hline 2010 & 7,403 \\
\hline 2012 & 7,054 \\
\hline 2014 & 9,882 \\
\hline 2016 & 9,843 \\
\hline 2018 & 13,472 \\
\hline
\end{tabular}

5 INFRASTRUCTURE

\subsection{Health}

The massive tourist development has had important consequences to the demography and economy of the island. Several workers in the tourist industry are now settling on the island for 6-8 months, while others remain all year round. It reduced the internal migration of young people from Paros urban centers. The economic crisis that hit the country over the past decade has led many well-educated young people and scientists to look for employment opportunities abroad or in economically more developed areas of the country. This was also the case with Paros. But the development of the tourism industry has reversed this trend, and Paros appears to be attracting a number of different professional groups.

The medical infrastructure of the island is quite good, as there are both public and private units. Public infrastructure includes one Health Center, providing diagnostic tests and care; and six regional clinics staffed with general practitioners (GPs). There are two private clinics with many specialized MDs on the island. There are also many private doctors, dentists and physiotherapists. It must be mentioned that the number of private doctors has doubled in the last ten years. The development of the medical infrastructure is indispensable for attracting special tourists, such as families with young children, as well as older people.

\subsection{Roads}

Paros has one of the best networks of roads and public transport in the Cyclades. The KTEL buses serve visitors and permanent residents, with a variety of routes and vehicles. All villages are linked both to each other and to the two large towns on the island, Paroikia and Naoussa, all year round. In summer months the routes, particularly to Naoussa, continue on through the early hours of the morning, with more frequent routes going to and from the port.

\subsection{Electricity}

The electric grid is expanding in Paros, with the help of EU funding. The project is expected to be completed by 2019: it will provide reliable and sufficient electrical power to supply the islands of Syros, Paros, Tinos and Mykonos for the next 30 to 40 years. This specific scheme involves the electricity supply from the subsystems of Lavrio and Syros, and Syros and Mykonos, and it includes: land acquisition, construction work such as underground and 
submarine cable connections, the building of a substation link to Lavrio, and outdoor connecting devices.

\section{TOURISM CARRYING CAPACITY INDICATORS}

Indicators of sustainability point to areas where the links between the economy, environment and society are weak. They allow one to realize where the problematic areas are, so as to suggest a solution policy for each indicator [18]-[20].

The main objective of the first group of variables is the rating of environmental characteristics and infrastructure for the area. This group includes twelve out of sixteen variables (Table 10): the score for each one is obtained by using questionnaires and qualitative indicators for each area.

Table 10: Carrying capacity indicators for Paros and the other Greek islands.

\begin{tabular}{|l|c|c|c|l|}
\hline & & Paros & Greek islands & \\
\hline & & Mean & Mean & \\
\hline V1 & $(\%)$ & 70 & 27.94 & Urban waste management \\
\hline V2 & $(\%)$ & 0 & 54.64 & Legality of buildings \\
\hline V3 & $(\%)$ & 60 & 84.94 & Protection against noise nuisance \\
\hline V4 & $(\%)$ & 80 & 57.05 & Garbage management \\
\hline V5 & $(\%)$ & 50 & 64.64 & Protection against pesticide usage \\
\hline V6 & $(\%)$ & 0 & 77.49 & Over-pumping of sea water \\
\hline V7 & $(\%)$ & 70 & 66.77 & Sufficient quantity of water resources \\
\hline V8 & $(\%)$ & 70 & 75.15 & Sufficient quality of drinking water \\
\hline V9 & $(\%)$ & 100 & 71.83 & Fire avoidance \\
\hline V10 & $(\%)$ & 80 & 80.68 & Forest clearance \\
\hline V11 & $(\%)$ & 50 & 71.79 & Conservation of the landscape \\
\hline V12 & $(\%)$ & 0 & 66.51 & Adequacy of green areas \\
\hline V13 & & 802.8 & 61.15 & Beds per kilometer of beach \\
\hline V14 & & 92,917 & 38.04 & Beds per square kilometer \\
\hline V15 & & 1,4054 & 58.55 & Beds per inhabitants \\
\hline V16 & & 0.18 & 15.38 & Blue flags per kilometer of beach \\
\hline
\end{tabular}

The second group consists of four variables (Table 11). The score is derived by using quantitative data and quantitative indicators. It should be noted that for quantitative indicators 13-15 high scores correspond to a large burden on the environment; and therefore, the variable should have low scores in the model. For reversal and mapping of the value of each indicator onto a grade scale of a maximum of 100, a descriptive analysis was used, the extreme value was excluded and the minimum tolerable limits for environmental burden were defined, based on the environmental literature.

Table 11: Carrying capacity indicators for Paros.

\begin{tabular}{|c|c|c|c|c|c|}
\hline PAROS & Mean & SD & & Mean & SD \\
\hline I13 $(\%)$ & 19.72 & $*$ & Ground & $75(\%)$ & $*$ \\
\hline I14 (\%) & 0 & 0 & Water & $70(\%)$ & $*$ \\
\hline I15 $(\%)$ & 0 & $*$ & Nature & $46(\%)$ & $*$ \\
\hline I16 $(\%)$ & 17.8 & $*$ & Score & $30.5(\%)$ & $*$ \\
\hline
\end{tabular}


This model can help us to evaluate the policies of the stakeholders and to express infrastructure solutions for each parameter.

In the Prokopiou-Tselentis model, the indicators for waste management, pressure on the coast line, illegal building, shore and marine pollution, and the use of fresh water resources have been used, in order to address the sustainability profile of tourist development in the Greek Islands. The proposed model is based on sixteen variables, which take values from 0 to 100 . These sixteen variables can be divided into two different groups.

The main objective of the first group of variables is the rating of environmental characteristics and infrastructure for the area; the group includes twelve of the sixteen variables and the score for each one of these variables, obtained by using questionnaires or personal observation, and the qualitative indicators for each area.

All the variables for the island of Paros have a median-high between $60 \%$ and $100 \%$, indicating that urban waste management (V1), protection against noise nuisances (V3), garbage management (V4), a sufficient quantity of water resources (V7), sufficient quality for the drinking water (V8), fire avoidance (V9) and forest clearance (V10) are efficient. The legality of buildings (V2), protection against usage of pesticides (V5), over-pumping of sea water (V6), conservation of the landscape (V11) and adequacy of green areas (V12) was found to be lacking in efficiency. Regarding the legality of buildings, the Paros municipality has started to pull down illegal buildings, as the building environment is protected in order to preserve the architectural character of Paros and the Cyclades islands.

The second group consists of four variables. It should be noted that for these indicators, a high score corresponds to a large burden on the environment. We converted the values to a 0-100 scale, using descriptive analysis while minimum tolerable limits for environmental burden were defined based on the environmental literature.

The number of beds per kilometer of beach (V13), beds per square kilometer (V14), beds per inhabitants (V15) and blue flags per kilometer of beach (V16) indicate that tourism impacts seriously on the island's environment, as the Blue Flag Program is not widely used on Paros' beaches.

\section{SWOT ANALYSIS}

After collecting data from field surveys, the following conclusions have been drawn up:

\subsection{Strengths}

1. Strong geographical location. The destination is located near Athens. One can reach the island by boat in 4 hours from Piraeus, or 2 hours by speedboat. The island is a well-known international Greek destination. Even though the tourism development of the island started in the early 1960 s, it still remains a famous choice.

2. The tourist infrastructure is sufficient, the tourist demand is sufficiently covered by the existing bed capacity (the season starts in May and ends in September), the catering and accommodation services are above average; however, a lot of the hotels and "rooms to let" do need renovation. The built environment in the city is beautiful, as the traditional architectural character has been preserved.

3. The tourism stakeholders are collaborating with each other, but do not have any economic resources for tourism destination promotion, as their annual turnover is limited.

4. Natural resources are not unlimited, as the island is small. 


\subsection{Weaknesses}

1. Generally, the professional skills of the tourism staff are unremarkable; most hotel employees are not graduates from tourism schools. Moreover, there are no established seminars for these employees.

2. There is reduced tourist demand in winter.

3. The new airport, is not yet widely used for international flights.

\subsection{Opportunities}

1. The internet e-booking.

2. The increasing importance of new technologies for online advertising.

3. The high cultural profile of the destination.

4. The maritime history and ancient history.

5. The local products.

6. The ability for thematic tourism development.

7. Promoting food and gastronomic culture.

\subsection{Threats}

1. Strong competition from the other Greek islands.

2. Competition from other islands of the Cyclades.

3. Poor visibility, due to low financial resources for marketing.

\section{DISCUSSION}

\subsection{The Paros municipality program}

The municipality's program for 2019 foresees its participation in 18 tourism exhibitions, as well as special promotional activities, which consist of [21]:

1. A campaign that will be run in digital media, under a promo hashtag.

2. The design of a digital ecosystem for the promotion of the experiences that the island offers. The digital ecosystem will enable partners to share digital platforms for a mutually beneficial purpose.

3. The creation of social media channels for every form of tourism offered on the island, with short videos in both English and Greek.

4. The creation of a yearly events calendar for the promotion of Paros' annual activities, and its link to existing online ticket and hotel booking systems.

5. The promotion of local enterprises that operate all year round, through a special campaign.

6. The creation of a virtual tour of Paros, which will be presented in future exhibitions in Greece and abroad.

\subsection{Proposals}

Tourist development indicators for Paros lead us to conclude that the tourism industry should focus on the expansion of the tourist season, accompanied by an occupancy of over $50 \%$ during April and October. The organized protection and development of environmentally sensitive areas could attract visitors with varied interests. Extension of tourism services for the spring season could be improved, by developing and marketing novel tourist activities on 
the island (mountaineering, cultural events, conferences, and more; with municipality support for gaining international charter flights.

We believe that cultural and religious tourism could be improved by upgrading the quality and the operation of several historical, cultural, and religious monuments and museums of Greece. The history of the island is a comparative advantage for the local cultural product.

Medical tourism, which is an extremely interesting growth opportunity, with adequate qualified medical personnel, should be combined with investments in facilities and infrastructure. The private hospitals on Rhodes could support these medical tourism services.

Congress-related tourism: The island could become a center for congress tourism, for international organizations and for companies. On Paros Island there are some modern conference centers, found in hotels across the coastal zone. Composite tourist accommodation cottages, such as in wineries in traditional villages and new districts, could utilize the new relevant law that allows for residence permits for non-residents who invest in real estate. The Paros villages are rich in culture; and some of the rural production presents a unique environment. Completion of urban waste treatment plants and networks for the use by the whole of Paros, restriction of illegal buildings in its towns and along the coastline, as well as control of hotel waste management systems is crucial.

The choice of a holiday destination is a significant lifestyle indicator for today's inspirational consumers, and the places where they choose to spend their squeezed in vacation time and hard-earned income does increasingly have to have an emotional appeal, high conversational capital and even celebrity value. Travel is an experience, and destination branding is an approach to managing and organizing tourist areas.

Alternative tourist development is conceptually related to sustainable development; it includes approaches to deal with development and economic options, to prevent environmental damage, and to involve the public and stakeholders in the decision-making processes. It has been proposed that serious efforts must be made in the direction of formulating viable policies, and in developing tools for effective implementation and control.

The upgrading of the tourism product is supported by important initiatives of the Greek government and the Greek Tourism Organization, as with the Hellenic Chamber of Hotels, and is considered one of the most strategic growth drivers of the Greek economy.

\section{REFERENCES}

[1] Briassouls, H., Policy and practice, sustainable development and its indicators: Through a (planner's) glass darkly. Journal of Environmental Planning and Management, 44(3), pp. 409-427, 2001.

[2] Zannou, V., Guide of Socio-Economic Studies for the Integrated Management of the Water Environment, 1999.

[3] Vassilopoulou, V. et al., Application of an ecosystem management approach in a coastal area in western Greece. Coastal Processes III, eds. C.A. Brebbia \& G. Rodriguez, WIT Press: Southampton and Boston, pp. 103-114, 2013.

[4] Prokopiou, D.G., Tselentis, B.S., Bousbouras, D. \& Toanoglou, M., Carrying capacity assessment in tourism: The case of Dodecanese Archipelago. The ravage of the planet. Presented at First International Conference on the Management of Natural Resources, Sustainable Development and Ecological Hazards, Bariloche, Argentina, 2006.

[5] Ntibanyurwa, A., Tourism as a factor of development. Sustainable Tourism II International Conference, Bologna, Italy, 2006.

[6] Priestley, G.K., Edwards, J.A \& Coccossis, H., Sustainable tourism-European experiences. CAB International, p. ix, 1996. 
[7] Navarro Jurado, E. et al., Carrying capacity assessment for tourist destinations. Methodology for the creation of synthetic indicators applied in a coastal area. Tourism Management, 33, 2012.

[8] Janvier-Blancas, F.J., Gonzalez, M., Lozano-Oyola, M. \& Perez, F., The assessment of sustainable tourism: Application to Spanish coastal destinations. International Journal Ecological Indicators, 10, 2010.

[9] Coccosis, H. \& Mexa, A., Challenge of Tourism Carrying Capacity Assessment, Ashgate, 2004.

[10] Hadjibiros, K., Aravantinou, M. \& Lapsidou, C., Organization and evaluation of a sustainable island network. International Journal of Sustainable Development and Planning, 6(1), pp. 13-20, 2011.

[11] Petrosillo, I., De Marco, A., Botta, S. \& Comoglio, C., EMAS in local authorities: Suitable indicators in adopting environmental management systems. Ecological Indicators, 10, 2011.

[12] Navarro Jurado, E. et al., Carrying capacity assessment for tourist destinations. Methodology for the creation of synthetic indicators applied in a coastal area. Tourism Management, 33, 2012.

[13] Prokopiou, D.G., Tselentis, B.S., Mavridoglou, G. \& Lagos, D., Prototype model of carrying capacity in tourism: the implementations for the island of Rhodes. European Scientific Journal, 2 (Special edition), 2014.

[14] Prokopiou, D.G., Mavridoglou, G., Toanoglou, M. \& Tslentis, B.S., Tourism development of the Cyclades Islands: Economic, social and carrying capacity assessment of the consequences. WIT Transactions on Ecology and the Environment, vol. 217, WIT Press: Southampton and Boston, 2018.

[15] Prokopiou, D.G., Environmental management of coastal zones and tourism. PhD dissertation, University of Piraeus, Piraeus, 2019.

[16] Official Webpage of Hellenic Ministry of Tourism, 2019. www.visitgreece.com.

[17] Official Webpage of Municipality of Paros, 2019. www.paros.gr.

[18] Hammond, A., Adriaanse, A., Rodenbourg, E., Bryant, D. \& Woodward, R., Environmental Indicators! A Systematic Approach to Measuring and Reporting on Environmental Policy Performance in Context of Sustainable Development, World Resources Institute, 1995.

[19] Hadjibiros, K., Aravantinou, M. \& Lapsidou, C., Organization and evaluation of a sustainable island network. Sustainable Development and Planning, 6(1), 2011.

[20] Stein, I., Riley, J. \& Halberg, N., Issues of scale for environmental indicators. Agriculture, Ecosystems and Environment, 87, pp. 215-232, 2001.

[21] Greek Travel Pages Media, www.gtp.gr.

[22] Association of Greek Tourism Enterprises (INSETE), https://sete.gr/.

[23] Hellenic Statistical Authority (ELSTAT), www.statistics.gr/.

[24] Hellenic Civil Aviation Authority, www.ypa.gr/en/. 